\title{
ARTICLE OPEN Differences in spirometry interpretation algorithms: influence on decision making among primary-care physicians
}

\author{
Xiao-Ou He${ }^{1}$, Anthony D’Urzo ${ }^{1,2}$, Pieter Jugovic ${ }^{2}$, Reuven Jhirad ${ }^{2}$, Prateek Sehgal ${ }^{1}$ and Evan Lilly ${ }^{1}$
}

BACKGROUND: Spirometry is recommended for the diagnosis of asthma and chronic obstructive pulmonary disease (COPD) in international guidelines and may be useful for distinguishing asthma from COPD. Numerous spirometry interpretation algorithms (SIAs) are described in the literature, but no studies highlight how different SIAs may influence the interpretation of the same spirometric data.

AIMS: We examined how two different SIAs may influence decision making among primary-care physicians.

METHODS: Data for this initiative were gathered from 113 primary-care physicians attending accredited workshops in Canada between 2011 and 2013. Physicians were asked to interpret nine spirograms presented twice in random sequence using two different SIAs and touch pad technology for anonymous data recording.

RESULTS: We observed differences in the interpretation of spirograms using two different SIAs. When the pre-bronchodilator FEV ${ }_{1} /$ FVC (forced expiratory volume in one second/forced vital capacity) ratio was $>0.70$, algorithm 1 led to a 'normal' interpretation

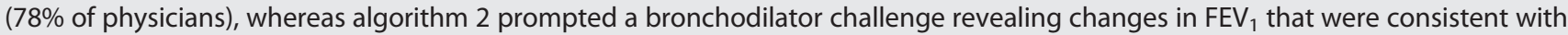
asthma, an interpretation selected by $94 \%$ of physicians. When the $\mathrm{FEV}_{1} / \mathrm{FVC}$ ratio was $<0.70$ after bronchodilator challenge but $\mathrm{FEV}_{1}$ increased $>12 \%$ and $200 \mathrm{ml}, 76 \%$ suspected asthma and $10 \%$ suspected COPD using algorithm 1 , whereas $74 \%$ suspected asthma versus COPD using algorithm 2 across five separate cases. The absence of a post-bronchodilator FEV $1 / F V C$ decision node in algorithm 1 did not permit consideration of possible COPD.

CONCLUSIONS: This study suggests that differences in SIAs may influence decision making and lead clinicians to interpret the same spirometry data differently.

npj Primary Care Respiratory Medicine (2015) 25, 15008; doi:10.1038/npjpcrm.2015.8; published online 12 March 2015

\section{INTRODUCTION}

Simple spirometry can identify airflow limitation in the office practice setting in a reliable, timely and affordable manner. The two most common chronic conditions encountered in primary care that are associated with airflow obstruction are asthma and chronic obstructive pulmonary disease (COPD). Although asthma and COPD share some common spirometric features, their underlying pathophysiology is quite distinct. For example, the inflammatory response in asthma is characterised, in part, by the presence of high numbers of eosinophils and mast cells, an inflammatory process that is very responsive to inhaled glucocorticosteroids, ${ }^{1}$ whereas in COPD the airways contain high numbers of neutrophils and macrophages among other inflammatory mediators, a process that appears to be much less responsive to treatment with inhaled glucocorticosteroids. ${ }^{2}$ Given these different clinical profiles, it is important to distinguish between asthma and COPD, particularly as first-line maintenance therapy in COPD is absolutely contra-indicated in asthma patients. ${ }^{1}$

Differentiating asthma from COPD is facilitated by having an understanding of how to interpret spirometric data, including an appreciation for the spirometric overlap that exists between asthma and COPD and how this may lead to disease misclassification. A recent report ${ }^{3}$ highlights that there is considerable variability among spirometry interpretation algorithms (SIAs) promoted for adoption in primary care. At present, it is not known how different SIAs may influence decision making among primary-care physicians. The reports of D'Urzo et al. ${ }^{4}$ outline important limitations of a SIA promoted for utilisation in primary care and they describe a new SIA ${ }^{5}$ designed to overcome some of these limitations. In this study, we attempt to validate both our critical appraisal of the older $\mathrm{SIAs}^{4}$ and features of the new SIA, which are consistent with current guidelines dealing with asthma and COPD diagnosis. ${ }^{5}$ In particular, we were interested in examining how two different SIAs (as stand-alone documents) could influence the interpretation of the same spirometric data among primary-care physicians. To our knowledge, this is the first study to examine how different SIAs may influence decision making among primary-care physicians.

\section{MATERIALS AND METHODS}

Data for this initiative were gathered from 113 primary-care physicians attending standardised accredited workshops at both provincial and National meetings in Canada between 2011 and 2013. The data gathering portion of the workshop focused on a critical appraisal of spirometry utilisation in primary care and included four components: (1) a preworkshop needs assessment comprising 10 questions; (2) a brief, $25 \mathrm{~min}$, didactic session on spirometry interpretation strategies; and (3) a session in which participants were asked to interpret, in multiple-choice format, nine different spirograms (Figure 1) presented twice in random sequence using two different SIAs. Table 1 shows the multiple-choice options used for interpreting the spirograms. SIAs used in our study include a version currently endorsed by the Ontario Thoracic Society, herein referred to as

\footnotetext{
${ }^{1}$ Faculty of Medicine, University of Toronto, Toronto, ON, Canada and ${ }^{2}$ Department of Family and Community Medicine at the University of Toronto, Toronto, ON, Canada. Correspondence: A D'Urzo (tonydurzo@sympatico.ca)

Received 11 July 2014; revised 19 October 2014; accepted 20 December 2014 
Case 1

\begin{tabular}{|c|c|c|c|c|c|}
\hline & \multicolumn{2}{|c|}{ PRE } & \multicolumn{2}{c|}{ POST } & \% Change \\
\hline & Best & $\%$ Pred & Best & $\%$ Pred & \\
\hline FVC & 3.06 & 75 & 3.35 & 82 & 10 \\
\hline FEV $_{1}$ & 1.90 & 60 & 2.18 & 69 & 15 \\
\hline FEV $1 / F V C^{2}$ & 62.2 & & 65.1 & & \\
\hline
\end{tabular}
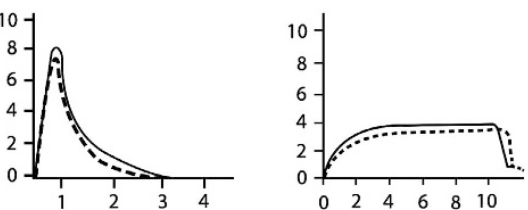

Case 4

\begin{tabular}{|c|c|c|c|c|c|}
\hline & \multicolumn{2}{|c|}{ PRE } & \multicolumn{2}{|c|}{ POST } & \multirow[t]{2}{*}{$\%$ Change } \\
\hline & Best & $\%$ Pred & Best & $\%$ Pred & \\
\hline FVC & 3.42 & 74 & 3.82 & 83 & 12 \\
\hline $\mathrm{FEV}_{1}$ & 1.91 & 52 & 2.13 & 58 & 12 \\
\hline $\mathrm{FEV}_{1} / \mathrm{FVC}$ & 55.8 & & 55.8 & & \\
\hline
\end{tabular}
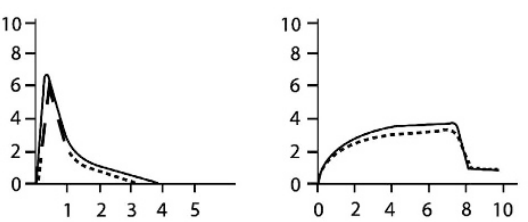

Case 7

\begin{tabular}{|c|c|c|c|c|c|}
\hline & \multicolumn{2}{|c|}{ PRE } & \multicolumn{2}{c|}{ POST } & \% Change \\
\hline & Best & $\%$ Pred & Best & $\%$ Pred & \\
\hline FVC & 3.62 & 81 & 4.26 & 96 & 18 \\
\hline FEV $_{1}$ & 2.21 & 62 & 2.77 & 78 & 25 \\
\hline FEV $_{1} /$ FVC & 61.2 & & 65.0 & & \\
\hline
\end{tabular}
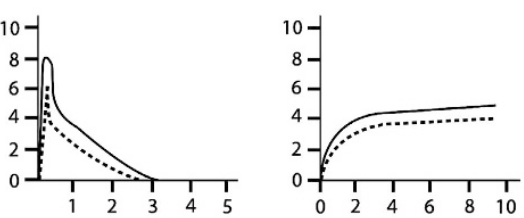

Case 2

\begin{tabular}{|c|c|c|c|c|c|}
\hline & \multicolumn{2}{|c|}{ PRE } & \multicolumn{2}{c|}{ POST } & \% Change \\
\hline & Best & $\%$ Pred & Best & $\%$ Pred & \\
\hline FVC & 5.75 & 108 & 6.05 & 114 & 5 \\
\hline FEV $_{1}$ & 4.03 & 92 & 4.78 & 109 & 19 \\
\hline FEV $/$ /FVC $^{2}$ & 70.2 & & 79.0 & & \\
\hline
\end{tabular}
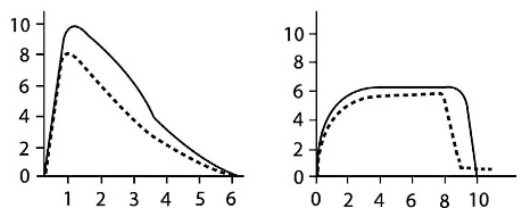

Case 5

\begin{tabular}{|c|c|c|c|c|c|}
\hline & \multicolumn{2}{|c|}{ PRE } & \multicolumn{2}{|c|}{ POST } & \multirow[t]{2}{*}{$\%$ Change } \\
\hline & Best & $\%$ Pred & Best & $\%$ Pred & \\
\hline FVC & 3.26 & 90 & 3.74 & 104 & 15 \\
\hline FEV, & 1.80 & 61 & 2.17 & 73 & 20 \\
\hline $\mathrm{FEV}_{1} / \mathrm{FVC}$ & 55.4 & & 58.0 & & \\
\hline
\end{tabular}
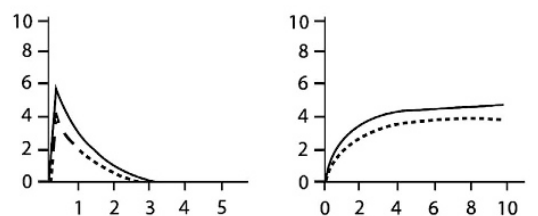

Case 8

\begin{tabular}{|c|c|c|c|c|c|}
\hline & \multicolumn{2}{|c|}{ PRE } & \multicolumn{2}{|c|}{ POST } & \multirow[t]{2}{*}{$\%$ Change } \\
\hline & Best & $\%$ Pred & Best & $\%$ Pred & \\
\hline FVC & 2.69 & 74 & 3.63 & 99 & 35 \\
\hline $\mathrm{FEV}_{1}$ & 1.44 & 49 & 1.86 & 64 & 29 \\
\hline $\mathrm{FEV}_{1} / \mathrm{FVC}$ & 53.6 & & 51.4 & & \\
\hline
\end{tabular}

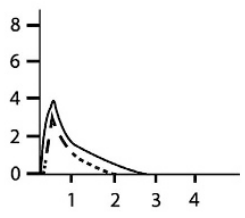

Pre bronchodilator: - - _ - _ - _ -

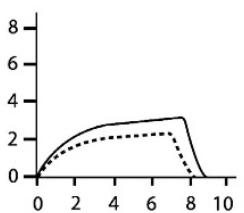

Post bronchodilator:
Case 3

\begin{tabular}{|c|c|c|c|c|c|}
\hline & \multicolumn{2}{|c|}{ PRE } & \multicolumn{2}{|c|}{ POST } & $\%$ Change \\
\hline & Best & $\%$ Pred & Best & $\%$ Pred & \\
\hline FVC & 4.83 & 99 & 4.93 & 101 & 2 \\
\hline $\mathrm{FEV}_{1}$ & 3.32 & 82 & 3.70 & 92 & 12 \\
\hline $\mathrm{FEV}_{1} / \mathrm{FVC}$ & 68.6 & & 75.1 & & \\
\hline
\end{tabular}
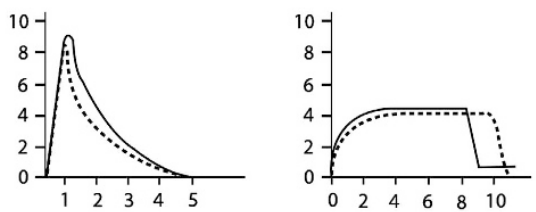

Case 6

\begin{tabular}{|c|c|c|c|c|c|}
\hline & \multicolumn{2}{|c|}{ PRE } & \multicolumn{2}{c|}{ POST } & \% Change \\
\hline & Best & $\%$ Pred & Best & $\%$ Pred & \\
\hline FVC & 2.84 & 73 & 3.50 & 90 & 23 \\
\hline FEV $_{1}$ & 2.20 & 70 & 2.64 & 84 & 20 \\
\hline FEV $_{1} /$ FVC & 77.4 & & 75.4 & & \\
\hline
\end{tabular}

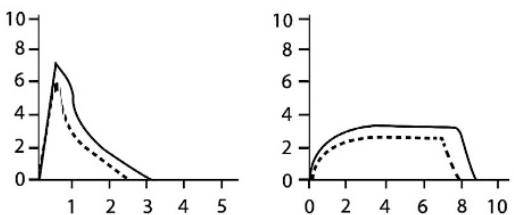

Case 9

\begin{tabular}{|c|c|c|c|c|c|}
\hline & \multicolumn{2}{|c|}{ PRE } & \multicolumn{2}{c|}{ POST } & \% Change \\
\hline & Best & $\%$ Pred & Best & $\%$ Pred & \\
\hline FVC & 5.02 & 102 & 4.84 & 98 & -3 \\
\hline FEV $_{1}$ & 3.33 & 84 & 3.84 & 94 & 15 \\
\hline FEV $1 / F V C$ & 66.4 & & 79.3 & & \\
\hline
\end{tabular}
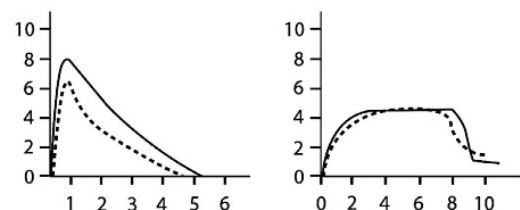

Figure 1. Nine different spirograms used in physician interpretation.

Table 1. Multiple-choice options for all nine spirograms per algorithm

\begin{tabular}{cl}
\hline Algorithm 1 & \\
A & Further testing with full PFT's \\
B & Suspect asthma \\
C & Suspect COPD \\
D & Normal \\
E & Restrictive disease \\
F & Unsure \\
& \\
Algorithm 2 & \\
A & Asthma versus COPD \\
B & Consistent with asthma \\
C & Restrictive disease (refer to specialist) \\
D & Unsure \\
\hline
\end{tabular}

Abbreviations: COPD, chronic obstructive pulmonary disease; PFT, pulmonary function test.

algorithm 1, and a newly developed SIA by the Primary Care Respiratory Alliance of Canada-algorithm 2. Figures 2 and 3 present the different algorithms, respectively. (4) A post-test comprising four questions relating to knowledge about spirometric diagnostic criteria on asthma and COPD diagnosis that had already been asked in the pre-workshop needs assessment in component 1 . Responses in components 1, 3 and 4 were captured in real time and anonymously using touch pad technology (remote data capture devices). ${ }^{6}$ Although the spirometric criteria for COPD in components 1 and 4 was defined as a reduction in the FEV $1 / F V C$ (forced expiratory volume in one second/forced vital capacity) ratio below 0.70 , component 2 did include mention of the lower limit of normal approach, which takes into account how age-associated decreases in $\mathrm{FEV}_{1} / \mathrm{FVC}$ ratio may lead to over-diagnosis in elderly individuals. ${ }^{2}$

Participants did not have prior knowledge about the content in any of the components. This approach permitted a non-biased design relating to the critical appraisal process, anonymous data capture and data storage in real time. Participants were advised that responses to any component items would be voluntary and that the data collected could be used for research purposes. The time allocated for response to each question was standardised as follows: $30 \mathrm{~s}$ for component 1 and component 4 questions, and $90 \mathrm{~s}$ for component 3 questions. This paper only deals with data obtained from component 3. During component 2, both SIAs were reviewed as stand-alone documents; no questions relating to the SIAs were addressed until the interpretation session was completed and all data were captured and stored. The only inclusion criteria was registering for the workshop. Descriptive statistics were used for data analysis. This initiative was submitted to the ethics committee at the University of Toronto and deemed to be a quality improvement study that did not 

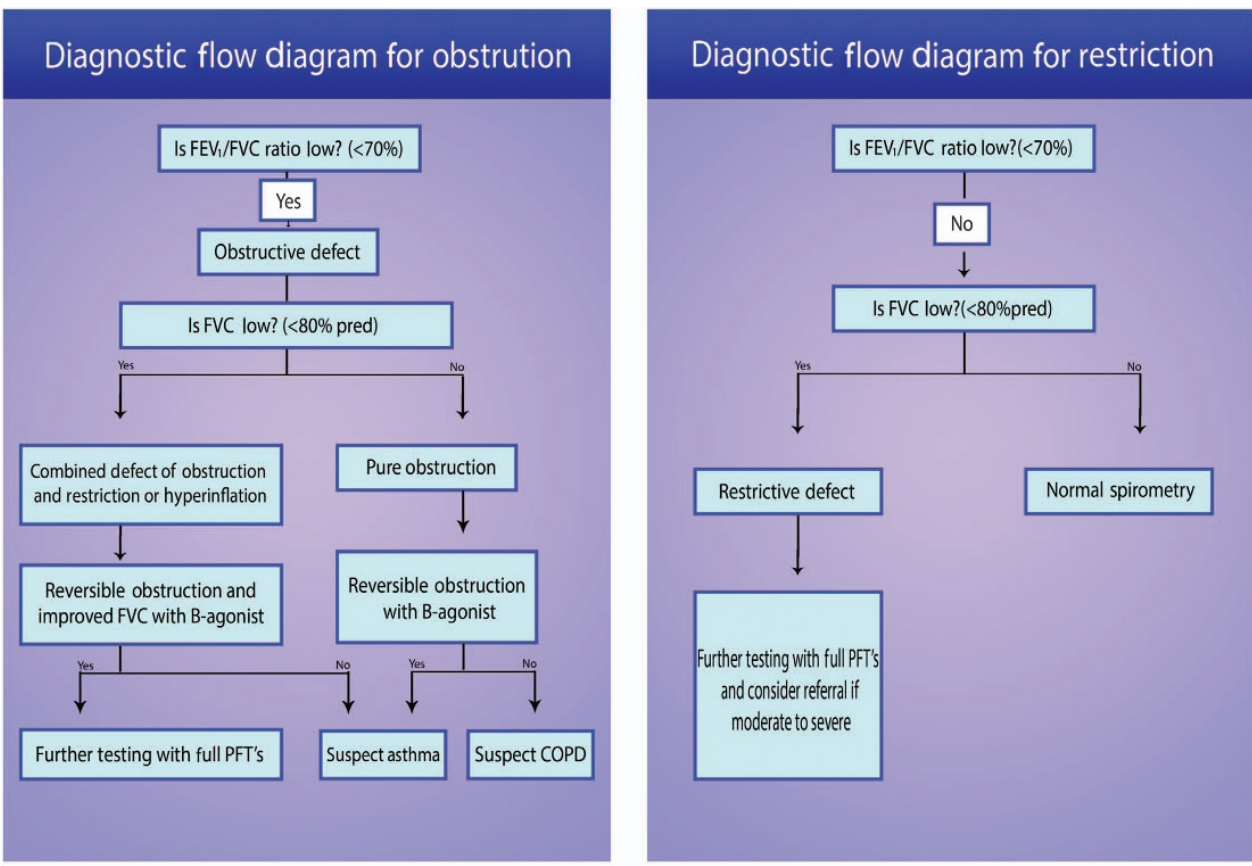

FEV : Maximal volume of air exhaled after a maximal inhalation in the first second of a forced exhalation.

FVC: Maximal volume of air exhaled after inhalation during a forced exhalation.

PFT: Pulmonary function test.

COPD: Chronic obstructive pulmonary disease.

Figure 2. Spirometry interpretation algorithm endorsed by the Ontario Thoracic Society (algorithm 1).

Primary care respiratory alliance of canada (PCRC)

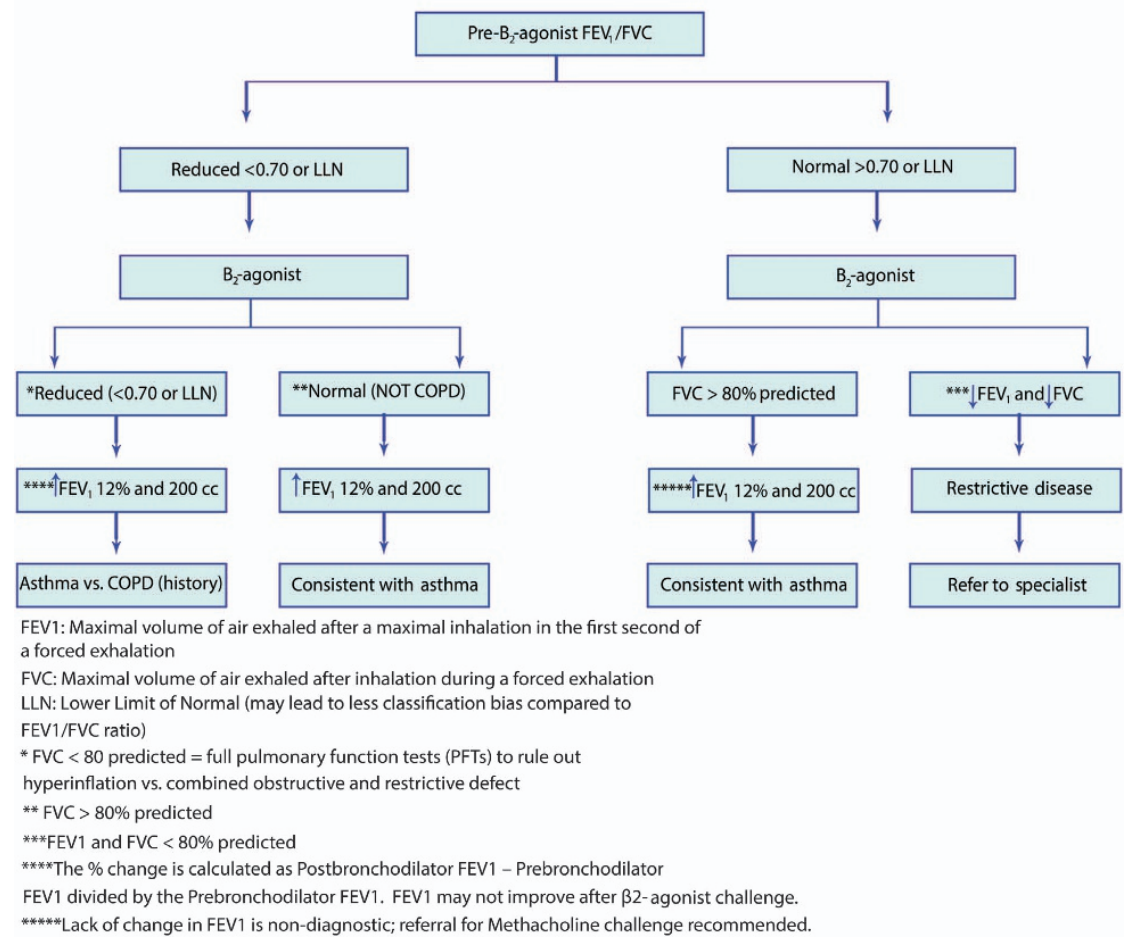

Figure 3. Spirometry interpretation algorithm from the Primary Respiratory Alliance of Canada (algorithm 2). 
Table 2. Physician's multiple-choice answers by percent across nine spirometric cases interpreted using two different SIAs $(n=109)$

\begin{tabular}{|c|c|c|c|c|c|c|c|c|c|}
\hline Cases & 1 & 2 & 3 & 4 & 5 & 6 & 7 & 8 & 9 \\
\hline \multicolumn{10}{|c|}{ Algorithm 1} \\
\hline A & 25 & 0 & 2 & 12 & 2 & 29 & 4 & 9 & 0 \\
\hline B & 47 & 16 & 71 & 72 & 89 & 12 & 88 & 82 & 57 \\
\hline C & 21 & 4 & 21 & 12 & 7 & 3 & 6 & 3 & 33 \\
\hline D & 4 & 78 & 6 & 0 & 1 & 32 & 0 & 0 & 4 \\
\hline$E$ & 1 & 1 & 0 & 3 & 1 & 24 & 2 & 5 & 4 \\
\hline$F$ & 2 & 1 & 0 & 1 & 0 & 0 & 0 & 1 & 2 \\
\hline \multicolumn{10}{|c|}{ Algorithm 2} \\
\hline A & 83 & 1 & 10 & 77 & 69 & 6 & 76 & 64 & 4 \\
\hline B & 12 & 94 & 83 & 13 & 28 & 82 & 22 & 29 & 87 \\
\hline C & 1 & 2 & 1 & 7 & 3 & 10 & 1 & 1 & 3 \\
\hline D & 4 & 3 & 6 & 3 & 0 & 2 & 1 & 6 & 6 \\
\hline
\end{tabular}

require formal ethics review. Spirometry data were acquired in accordance with international guidelines. ${ }^{7}$

\section{RESULTS}

Of the 113 participants who completed the study, 4 were removed (4\%) from analyses because of an inability to retrieve complete data sets. The final number of participants used for analyses is 109 . The results are presented in Table 2.

Three key differences were observed in the interpretation of same spirograms using two different SIAs. When the prebronchodilator $\mathrm{FEV}_{1} / \mathrm{FVC}$ ratio was $>0.70$, algorithm 1 led to a 'normal' or 'restrictive defect/further testing' interpretation, whereas algorithm 2 prompted a bronchodilator challenge revealing changes in $\mathrm{FEV}_{1}$ that were 'consistent with asthma'. Cases 2 and 6 had a pre-bronchodilator $\mathrm{FEV}_{1} / \mathrm{FVC}$ ratio of $>0.70$. Using algorithm 2, 94\% selected 'consisted with asthma' in case 2 and $82 \%$ in case 6 . However, interpreting the same spirograms using algorithm 1 led to a 'normal' interpretation (78\%) for case 2 and $53 \%$ selected 'restrictive disease/further testing' for case 6. The presence of a post-bronchodilator $\mathrm{FEV}_{1} / \mathrm{FVC}$ decision node when $\mathrm{FEV}_{1} / \mathrm{FVC}$ ratio was normal in algorithm 2 allowed for the consideration of asthma despite data that appeared normal.

Differences in interpretation were also encountered when the pre- and post-bronchodilator $\mathrm{FEV}_{1} / \mathrm{FVC}$ ratio was less than 0.70 with a $\mathrm{FEV}_{1}$ increase of greater than $12 \%$ and $200 \mathrm{ml}$ after bronchodilator challenge. When participants were asked to interpret case 4 using algorithm 1,72\% of individuals selected 'suspect asthma'. Applying algorithm 2, however, 77\% selected 'asthma versus COPD' and only $13 \%$ selected 'consistent with asthma'. Similar results can also be seen in cases 5,7 and 8, which share spirometric resemblance to case 4 . The reliance of changes in $\mathrm{FEV}_{1}$ after bronchodilator challenge to distinguish asthma from COPD in algorithm 1 led to consideration of asthma despite the presence of data that were also consistent with COPD.

Last, differences were also observed when the prebronchodilator $\mathrm{FEV}_{1} / \mathrm{FVC}$ ratio was less than 0.70 with a postbronchodilator $\mathrm{FEV}_{1} / \mathrm{FVC}$ ratio $>0.70$. Two cases fall under this category: cases 3 and 9 . Using both algorithms 1 and 2, the majority of participants agreed that the spirograms were consistent with asthma for both cases. When participants interpreted case 3 and case 9 using algorithm 1, 21 and 33\% suspected COPD and 71 and $57 \%$ suspected asthma, respectively. This was not the case with algorithm 2, in which a higher portion of participants suspected asthma (83 and 87\%) and fewer individuals considered COPD.

\section{DISCUSSION}

Main findings

The results of the present study highlight that the use of two different SIAs as stand-alone documents results in differences in interpretation of the same spirometric data among family physicians. Although sharing common spirometric indices, differences between the two SIAs in relation to logic string and decision node organisation would appear to account for the observed differences reported here. Our findings suggest a need for standardisation of SIAs to minimise variation in data interpretation.

\section{Strength and limitations of this study}

A limitation of our study relates to the exclusive use of spirograms where the $\mathrm{FEV}_{1}$ improved by at least $12 \%$ and $200 \mathrm{ml}$ after bronchodilation, a strategy used to emphasise that partial reversibility is common among COPD patients. ${ }^{8}$ Inclusion of spirograms in which the $\mathrm{FEV}_{1}$ did not improve by at least $12 \%$ and $200 \mathrm{ml}$ after bronchodilation would certainly reflect real-life conditions $^{9-12}$ but would not likely influence our general findings for the reasons outlined below. Another limitation relates to algorithm 2 where there is no logic string leading to a decision node, where the $\mathrm{FEV}_{1}$ does not improve by $12 \%$ and $200 \mathrm{ml}$ when the $\mathrm{FEV}_{1} / \mathrm{FVC}$ ratio remains below 0.70 or the lower limit of normal after bronchodilation. However, this omission should not influence clinical decision making, as bronchodilator-induced reversibility is not used to include or exclude COPD diagnosis, and thus the clinician is still left with the task of considering clinical historical factors to facilitate distinction between asthma and COPD. A strength of algorithm 2 relates to the inclusion of a logic string where bronchodilator challenge is recommended despite the finding of a normal $\mathrm{FEV}_{1} / \mathrm{FVC}$ ratio, a strategy that recognises that most asthmatics encountered in primary care $^{9-11,13}$ have normal lung function and some may exhibit FEV reversibility criteria at the time of testing. For those patients with normal lung function and lack of FEV 1 reversibility, methacholine challenge testing is recommended. By contrast, algorithm 1 and other $\mathrm{SIAs}^{3}$ do not contain a logic string that prompts bronchodilator challenge when $\mathrm{FEV}_{1} / \mathrm{FVC}$ ratio is normal, a feature that may lead to under-diagnosis of asthma as most mild asthmatics in primary care may present with normal lung function and may fall into this spirometric category. ${ }^{14}$

Although our study design allows for evaluation of variability of interpretations owing to algorithms between different participants, it is less clear how variability within participants may have influenced our findings. With respect to the latter, we did note that for cases 5, 7 and 8, which share close spirometric resemblance to case 4 , the interpretations were comparable for each algorithm, suggesting a comparable response both within and between individuals. We are not sure whether this would also be the case with spirograms containing different features from those in the cases highlighted above. As stated previously, it is very likely that the differences in interpretation reported here are owing to variations in logic string and decision node organisation between the two algorithms. Although there are spirometric diagnostic criteria for asthma and COPD outlined in various guidelines, $^{1,2}$ to date, there are no SIAs that promote a standardised approach to data interpretation. Our study is the first to show that built-in differences in SIAs may lead physicians to interpret the same spirometry data differently if these documents are used as stand-alone aids.

We did not record the exact time taken by participants to interpret the same spirometric data using the two SIAs, because the allowable time for each interpretation was standardised at $90 \mathrm{~s}$. However, as stand-alone documents, both SIAs appeared to afford most participants with adequate time to complete each interpretation. This finding is reassuring, as diagnostics aids are 
probably more likely to be incorporated into practice if their use facilitates prompt decision making in conjunction with an appropriate clinical history. Given our inclusion criteria, we cannot determine how demographic factors may have influenced spirometry interpretation among the physicians in our study. Given the descriptive nature of our comparisons between SIAs, it is difficult to predict the clinical implications of the differences we identified. Furthermore, as our data were gathered within a quality improvement framework, this may limit wider external application of our findings.

Interpretation of findings in relation to previously published work In a previous report, ${ }^{3}$ we describe that there was considerable variation among SIAs promoted for adoption in primary care. For example, some SIAs lacked logic strings and decision nodes that would guide the user to a post-bronchodilator $\mathrm{FEV}_{1} / \mathrm{FVC}$ ratio, making it difficult to establish a spirometric diagnosis of COPD. Furthermore, in some cases, the finding of a $\mathrm{FEV}_{1} / \mathrm{FVC}$ ratio $>0.70$ or the lower limit of normal led to a 'normal' interpretation and would not prompt a bronchodilator challenge, a feature that would prevent detection of post-bronchodilator changes in $\mathrm{FEV}_{1}$ that would satisfy the spirometric criteria for asthma diagnosis. ${ }^{4,5}$ In other SIAs, changes in $\mathrm{FEV}_{1}$ after bronchodilator challenge would be used to distinguish asthma from COPD, a strategy that does not acknowledge that many COPD patients (more than $50 \%$ in some reports) may also fulfil $\mathrm{FEV}_{1}$ reversibility criteria., ${ }^{4,5}$ Finally, it is important to consider other tests ${ }^{1,2}$ to improve diagnostic clarity when the post-test probabilities remain intermediate, including exhaled nitric oxide, diffusion capacity for carbon monoxide, and sputum eosinophils, to name a few.

Implications for research, policy and practice

The content and organisational differences in logic strings and decision nodes between the two SIAs described here appear to translate into differences in interpretation of the same spirometric data. We believe that algorithm 2 would influence decision making in a manner that is more in keeping with current spirometric criteria for asthma and COPD diagnosis. ${ }^{1,2}$ For example, algorithm 2 was designed to overcome the limitations of various SIAs outlined above by including spirometric criteria described in both asthma and COPD management guidelines, ${ }^{1,2}$ and to take into account the considerable spirometric overlap between asthma and COPD. The latter underscores the critical importance of a thorough clinical history and should remind us that spirometry data alone may not be adequate to establish a clinical diagnosis. ${ }^{5}$

An important feature of this study was to validate both our critical appraisal of algorithm 1, Figure $2{ }^{4}$ and features of the more current, algorithm 2, Figure $3 .^{5}$ Algorithm 1, similar to other SIAs, ${ }^{3}$ lacks a logic string that leads to a decision node that includes a postbronchodilator $\mathrm{FEV}_{1} / \mathrm{FVC}$ ratio, making it difficult to establish a spirometric diagnosis of COPD based on current guidelines. ${ }^{2}$ Instead, a lack of improvement in $\mathrm{FEV}_{1}$ after bronchodilator is used to differentiate asthma from COPD. As it is well established that many patients who meet the spirometric diagnosis of COPD may also fulfil the $\mathrm{FEV}_{1}$ reversibility criteria for asthma diagnosis, ${ }^{1,8}$ algorithm 1 could lead the user to suspect asthma in many cases of COPD. For example, when the post-bronchodilator $\mathrm{FEV}_{1} / \mathrm{FVC}$ ratio was less than 0.70 with an $\mathrm{FEV}_{1}$ increase of greater than $12 \%$ and $200 \mathrm{ml}$, using algorithm 1 the majority of participants selected 'suspect asthma', whereas with algorithm 2 the majority of individuals selected 'asthma vs COPD' and the minority selected 'consistent with asthma'. As algorithm 2 takes into account the spirometric overlap between asthma and COPD, the user is guided to consider nonspirometric factors such as clinical history in establishing a clinical diagnosis. Although our study suggests that spirograms fulfilling spirometric criteria for both asthma and COPD are more likely to lead to an interpretation linked to asthma using algorithm 1, we are not certain whether this might be linked to a combination of factors, including greater awareness of spirometric criteria for asthma diagnosis and a lack of appreciation that many COPD patients may fulfil $\mathrm{FEV}_{1}$ reversibility criteria after bronchodilator challenge. Our findings do, however, underscore the importance of educating physicians about the pitfalls of using bronchodilator-induced changes in $\mathrm{FEV}_{1}$ to distinguish asthma from COPD. Given the spirometric overlap between asthma and COPD, a clinical diagnosis should not be assigned in the absence of a thorough clinical history and physical exam.

\section{Conclusions}

Our observations indicate that differences in SIAs appear to influence decision making among physicians. These findings do raise awareness about the importance of standardisation among SIAs. Further studies are required to determine the utility of SIAs used in conjunction with historical and physical examination findings for clinical diagnosis of asthma and COPD, and whether differences in interpretation between SIAs would lead to disease misclassification or inappropriate patient care in the clinical setting.

\section{ACKNOWLEDGEMENTS}

We thank the Department of Family and Community Medicine at the University of Toronto for their support.

\section{CONTRIBUTIONS}

$A D$ initiated the idea for the study and led the development of the protocol, supervised the administration and contributed to data analysis and writing of the paper. $\mathrm{X}-\mathrm{OH}$ participated in writing of the paper, data analysis, preparation of tables and statistics. All the other authors reviewed the paper and contributed to data analysis. AD is an Associate Editor of npj Primary Care Respiratory Medicine, but was not involved in the editorial review of, nor the decision to publish, this article.

\section{COMPETING INTERESTS}

The authors declare no conflict of interest.

\section{FUNDING}

We graciously thank the Department of Family and Community Medicine at the University of Toronto and the Comprehensive Research Experience for Medical Students for their funding and support of this study.

\section{REFERENCES}

1 Lougheed MD, Lemiere C, Ducharme FM, Licskai C, Dell DS, Rowe BH et al. Canadian Thoracic Society 2012 guideline update: diagnosis and management of asthma in preschoolers, children and adults. Can Respir J 2012; 19: 127-164.

2 O'Donnell DE, Aaron S, Bourbeau J, Hernandez P, Marciniuk DD, Balter M et al. Canadian Thoracic Society recommendations for management of chronic obstructive pulmonary disease-2007 update. Can Respir J 2007; 14: 5B-32B.

3 Marshall A. Spirometry algorithms may be in need of standardization. Pulm Rev 2010; 15: 1-5

4 D'Urzo AD, Tamari I, Bouchard J, Jhirad R, Jugovic P. Limitations to a spirometry interpretation algorithm. Can Fam Physician 2011; 57: 1153-1156.

5 D'Urzo AD, Tamari I, Jugovic P. New spirometry interpretation algorithm. Can Fam Physician 2011; 57: 1148-1152.

6 Turning Technologies Canada. Available at http://www.turningtechnologies.ca (last accessed 3 August 2013).

7 Miller MR, Hankinson J, Brusasco V, Burgos F, Casaburi R, Coates A et al. A Standardisation of spirometry. Eur Respir J 2005; 26: 319-338.

8 Tashkin DP, Celli B, Decramer M, Liu D, Burkhart D, Cassino C et al. Bronchodilator responsiveness in patients with COPD. Eur Respir J 2008; 31: 742-750.

9 Aaron SD, Vandernheen KL, Boulet LP, Mclvor A, FitzGerald JM, Hernandez P et al. Overdiagnosis of asthma in obese and nonobese adults. CMAJ 2008; 179: 1121-1131. 
10 Goldstein MF, Veza BA, Dunsky EH, Dvorin DJ, Belecanech GA, Haralabatos IC Comparisons of peak diurnal expiratory flow variation, postbronchodilator $\mathrm{FEV}(1)$ responses, and methacholine inhalation challenges in the evaluation of suspected asthma. Chest 2001; 119: 1001-1010.

11 Luks VP, Vandemheen KL, Aaron SD. Confirmation of asthma in an era of over diagnosis. Eur Respir J 2010; 36: 255-260.

12 Greiver M, Lang C, Hunchuck J, Rothchild K. Improving the diagnosis of asthma in a primary care practice. Can Fam Physician 2012; 58: 773-774.

13 Lusuardi M, De Benedetto F, Paggiaro P, Sanguinetti CM, Brazzola G, Ferri P et al. A randomized controlled trial on office spirometry in asthma and COPD in standard general practice. Chest 2006; 129: 844-852.

14 Smith AD, Cowan JO, Filsell S, McLachlan C, Monti-Sheehan G, P Jackson P et al. Diagnosing asthma: comparisons between exhaled nitric oxide measurements and conventional tests. Am J Respir Crit Care Med 2004; 169: 473-478.

(C) (1) This work is licensed under a Creative Commons Attributioncc) NonCommercial-ShareAlike 4.0 International License. The images or other third party material in this article are included in the article's Creative Common license, unless indicated otherwise in the credit line; if the material is not included under the Creative Commons license, users will need to obtain permission from the license holder to reproduce the material. To view a copy of this license, visit http:// creativecommons.org/licenses/by-nc-sa/4.0/ 